\title{
FROM “LOOKING FOR ALIBRANDI" TO "DOES MY HEAD LOOK BIG IN THIS?" The role of Australian teenage novels in reconceptualising racialised- gendered identities
}

\author{
Transforming Cultures eJ ournal, \\ Vol. 2 No 1, November 2007 \\ http:// epress.lib.uts.edu.au/journals/TfC
}

\section{Lana Zannettino}

\begin{abstract}
This paper undertakes a comparative analysis of three Australian teenage novels - Melina Marchetta's 'Looking for Alibrandi' (1992), Randa AbdelFattah's 'Does my Head Look Big in This?' (2005), and Morris Gleitzman's 'Girl Underground' (2004). Drawing from feminist post-structural and postcolonial theories, the paper examines how each author has constructed the racialised-gendered identities of their female protagonists, including the ways in which they struggle to develop an identity in-between minority and dominant cultures. Also considered is how each author inter-weaves race, gender and class to produce subjects that are positioned differently across minority and dominant cultures.

The similarities in how the authors have inscribed race and ethnicity on the subjectivities of their female characters, despite the novels being written at different points in time and focusing on different racial and ethnic identities, suggest that what it means to be a raced subject in Australia has more to do with the significance of all-at-once 'belonging' and 'not belonging' to the dominant culture, of 'inclusion' and 'exclusion' and of 'sameness' and 'otherness', than it has with the unique characteristics of biological race and ethnic identification. The paper argues that this kind of fiction carries with it an implicit pedagogy about race relations in Australia, which has the potential to subvert oppressive binary dualisms of race and gender by demonstrating possibilities for the development of hybrid cultural identities and 'collaborations of humanity'.
\end{abstract}

\section{Introduction}

Over the last decade or so media coverage and public discussion in Australia about women and Islam has almost exclusively been defined and understood in relation to provocative debates about the hijab and Sharia Law. The Muslim woman, both as subject and as sign, therefore, occupies a curiously paradoxical position in the 
Australian public consciousness - she is simultaneously the victim of Islamic tradition and a powerful signifier of its existence and perpetuation. These subject positionings have been fed by and continue to feed into politically driven interests that help to justify and sustain Australia's involvement in the so called war on terror but in so doing they have homogenised and fetishised Islamic women's individual subjectivities, causing them to be subsumed within the amorphous category of the 'other'. Thus, attempts within literature and popular culture to reconceptualise the racialised female subject have become increasingly important in the unveiling of the political fictions that have created the spectre of this monolithic 'other'. In this paper I draw on feminist poststructural and post-colonial theories to analyse three Australian teenage novels - Melina Marchetta's Looking for Alibrandi (1992), Randa Abdel-Fattah's Does my Head Look Big in This? (2005), and Morris Gleitzman's Girl Underground (2004). My purpose here is to show how diasporic identities are represented in contemporary Australian teenage literature, and in so doing, shed light on how these representations can potentially reconstruct the ways in which we view and understand racialised-gendered identities in this country, at both cultural and individual levels. At a cultural level, the reading of fiction is an important process in the assimilation of dominant cultural meanings about gender and race, making literature a significant instrument of cultural reproduction. At a more individual and psychodynamic level, "the positions and relations created in the text both relate to existing social and psychic struggle and provide a fantasy vehicle which inserts the reader into the text" (Walkerdine, 1984: $165)$.

It is not my intention in this paper to comment on the political perspectives of the authors of these novels, rather I focus here on how diasporic identities are mobilised within and through the texts' female protagonists, as if these characters are real and lived entities rather than fictional ones arising from the imaginations of the authors who created them. Whilst I do make comment on the potential impact of these texts on the young people who read them, I do so with the knowledge that audience responses to literature are always mediated by a range of often competing and conflicting discourses, the subject positions they afford, and the individual's specific historical, political and cultural circumstances. 
From a post-structural position, there is no reality that exists outside the individual's unique response to literary texts but rather a subjectivity that is both exposed and subject to discursive construction. I too am part of this 'audience' of readers and thus my 'interpretations' of the novels I examine here are also mediated by how I have come to be subjected by discourse, particularly by those that circulate within the realm of academia. My analysis, therefore, is just one of many possible analyses none of which can be viewed as definitive:

without any authorial guarantee concerning meaning, the critic's job is no longer to retrieve the meaning of a text, but rather, in the full knowledge that the meanings of the text are plural, to produce an interpretation which realises just one of the possibilities contained in the text (Jefferson, 1982: 90).

\section{About the three novels}

First published fifteen years ago in 1992, Looking for Alibrandi is a novel about a seventeen-year-old girl named Josephine Alibrandi who was born in Australia to Italian parentage. Published in 2005, Does my head look big in this? is a novel about a sixteenyear-old girl named Amal Abdel-Hakim who identifies as an 'Australian-PalestinianMuslim'. The third novel I focus on here is Girl Underground, which was published in 2004. This novel is about a twelve-year-old white Australian girl named Bridget White whose family engages in illegal yet harmless activities in order to make a living. All three novels are written from the point of view of their respective female protagonists, Josephine, Amal and Bridget whose 'first person' narratives are analogous to entries in a personal diary. Like other teenage fiction in the 'coming of age' genre, all three characters describe their hopes, dreams, fears and desires as well as the more typical adolescent concerns about 'fitting in' with peers, schoolwork, and relationships with friends and family. Ultimately, however, what these three novels have in common is that each undertakes an exploration of 'diaspora' in Australia and its material and psychological effects on the lives of everyday people.

In the first two novels, Josephine and Amal's 'coming of age' is profoundly connected to being a racialised subject in Australia, of all at once belonging and not belonging to the dominant culture, and their struggle to negotiate their racialised identities across diverse cultural terrains:

Josephine: I think I had it worst. My mother was born here so as far as the Italians were concerned we weren't completely one of them. Yet because my 
grandparents were born in Italy we weren't completely Australian (Marchetta 1992: 7).

Amal: I'm an Australian -Muslim-Palestinian. That means I was born an Aussie and whacked with some bloody confusing identity hyphens (AbdelFattah 2005: 5).

In the third novel, the female protagonist, Bridget, is a white Australian girl whose classed position and family's 'criminality' means that she too deals with alienation from the dominant culture. However, it is the diasporic subject rather than the classed one that is thematically central to this novel. It is important to make the point that whilst Bridget is also a 'raced' subject in terms of her 'whiteness', she cannot be viewed as a subject of diaspora. As Ashcroft, Griffiths and Tiffen (2001: 426) point out:

Of the many different peoples who have been scattered and dispersed throughout the world, only some of them can be called diasporic. For instance, we can talk about an Irish diaspora or an Indian or African diaspora but we rarely talk about an English diaspora. The question is one of power. It seems inappropriate to talk about the spread of a powerful colonizing people around the world as 'an exile' although some may experience it as such. Nor can we describe as a diaspora that cultural group that attains global dominance. Diasporas have come to mean cultural minorities, in social power if not always in number (e.g. the African diaspora in the Caribbean) and as such are always seen to be establishing their sense of identity and cultural affiliation, their sense of home, their sense of subject position, against the background of a 'majoritarian' rule.

Bridget's whiteness and class position, however, provide important leverage for the novel's examination of the pain and immorality of refugee detention in Australia. The novel's demonstration of Bridget's compassion for and friendship with child refugees Jamal and Bibi who are imprisoned in a desert detention centre is juxtaposed against her whiteness and its capacity to comfortably cushion the effects of her family's criminality and inferior class position:

Bridget: And now we're in Canberra, driving along the dark streets towards Menzies' place, I can see that the people here are kind too... And all over the lawns, nibbling the grass and cooling down in the sprinklers, are hundreds and hundreds of kangaroos. Only very kind people would share their city with hungry creatures that have come in from the bush. People with good and caring hearts. Which is why I'm sure that when we get to Menzies' place and I ask his dad to help Jamal and Bibi, his dad'll say yes (Gleitzman 2004: 87). 


\section{A place of ambivalent existence}

In this paper I use the terms 'diaspora' and 'diasporic identities' to refer to those people who live within and between two different worlds of ethno-cultural influence - a place of literal or imagined origin on the one hand and a place of relocation or displacement on the other. Put simply, the subject of diaspora occupies a place of ambivalent belonging and existence. The personal narratives of Salman Rushdie and Ien Ang provide a poignant illustration of the particular ambivalence produced for the subject of diaspora:

We are Hindus who have crossed the black water; we are Muslims who eat pork. And as a result [....] we are now partly of the West. Our identity is at once plural and partial. Sometimes we feel that we straddle two cultures; at other times, that we fall between two stools (Rushdie, 2006: 431).

I would describe myself as suspended in-between: neither truly Western nor authentically Asian; embedded in the West yet always partially disengaged from it; disembedded from Asia yet somehow enduringly attached to it emotionally and historically (Ang, 2001: 194).

As there is a fundamental ambivalence inherent in the human condition of diaspora, I discuss the diasporic identities created in the texts I examine here through the concept of hybridity. In very basic terms, hybridity can be defined as the emergence of new identities through the melding of different and often incongruous elements of ethnic identification. Hybridity has become an important conceptual tool in post-colonial theorising because it exerts the inescapable impurity of all cultures (Ang, 2001), it marks the impossibility of essentialism (Young, 1995) and it disrupts the idea of nation and national identity. Just as importantly, and for the purposes of this paper, the concept of hybridity has the potential to generate important insights into the intra-psychic experience of the subject of diaspora including the pain and awkwardness of being 'suspended in-between' and the potential of becoming anew by living with and through difference (Hall, 1990).

Homi Bhabha defines hybridity as a:

'liminal space in-between the designations of identity... an interstitial passage between fixed identifications [that] opens up the possibility of a cultural hybridity that entertains difference without an assumed or imposed hierarchy' (1994: 4). 
In this way, Bhabha and other post-structural and post-colonial theorists have identified a place of ambivalent existence for minority subjects who are situated between the 'same' and the 'other' - an emancipatory space that provides the potential for the development of hybrid identities that challenge oppressive binary oppositions. Bhabha (1994) goes on to suggest that opportunities for hybridisation open up spaces for negotiation where power is unequal but where agency still exists in the interstices of the exercise of power, which can give rise to new meanings for and about minority communities.

Ang (1996) is cautious of this position however based on her study of Asian women in Australia, which suggests that this place of ambivalence does not necessarily afford emancipation. According to Ang, the minority subject's occupation in the ambivalent space means that she can be confined as well as embraced, that "ambivalence is not only a source of power but also a trap, a predicament" (1996: 46). In this way, Ang warns against making broadly abstracted claims about and across differences because the power of ambiguity or hybridity in relation to the 'othered' subject's capacity to resist her 'otherness' is interchangeable across different situations and in relationship to gender and class considerations. Hence, "those who are collectively constituted as 'other' can be divided by multiple forms of power, and by social divisions within and between categories of identity, community and locality" (Ramazanoğlu, 2004: 111). Notwithstanding, Bhabha's concept is potentially illuminative in that it points to the significance for the subject of all-at-once 'belonging' and 'not belonging', of 'sameness' and 'otherness', and of 'inclusion' and 'exclusion'. Most importantly, the concept is inclusive of all races and ethnicities because it transcends discussion of the immutable peculiarities of race as markers of difference on the body and the psyche, focusing instead on the boundaries of 'same'/'other' that constitutes the diasporic subject's complex relationship with the broader cultural context. It is this aspect of Bhabha's theory that allows for a broad examination of the displacement of the raced subject in Australia across highly particular racial and ethnic identities.

\section{The gendered and classed signification of racialised identities}

Bhabha's concept of being in-between the designations of identity is especially relevant to my analysis of the first two novels in particular because it is not just the specific characteristics and manifestations of each girl's race and/or religion (although these do 
have signification about which I will speak later) that provide the greatest challenge to their 'coming of age'. Rather, it is their attempts to negotiate these racialised identities within and across gendered, classed, religious, and inter-generational configurations:

Josephine: No matter how much I hate Poison Ivy, I want to belong to her world. The world of sleek haircuts and upper-class privileges. People who know famous people and lead educated lives. A world where I can be accepted. Please, God, let me be accepted by someone other than the underdog (Marchetta 1992: 32).

I'll run one day. Run for my life. To be free and think for myself. Not as an Australian and not as an Italian and not as an in between. I'll run to be emancipated (Marchetta 1992: 40).

Amal: I can't believe I'm actually contemplating wearing the hijab to a snotty grammar school where you're seriously doomed to the noncool list if you're one issue behind on the latest Cleo fashion... What am I doing being all holy and stuff when I know I've got more chance of getting away with a Kelly Osborne look than I do covering my hair? (Abdel-Fattah 2005: 13)

It's Wednesday. The only people who haven't freaked out about my hijab have been Simone and Eileen... (Abdel-Fattah 2005: 57).

This morning I'm in the hallway when I overhear some girls talking about me next to the lockers. One of them says the word 'oppressed' and the other one is saying something about me looking like a dag... I walk slowly away, feeling like a boiling kettle of water about to whistle and screech (AbdelFattah 2005: 58).

As the extracts above suggest, both authors weave the threads of gender and class into the fabric of Josephine and Amal's ethno-cultural identifications. These gendered and classed dimensions add further layers of complexity and nuance to each girl's personal experience of diasporic subjectification. In this respect, both novels go some way to expose the ways that gender and class intersect with race to produce subjects that are positioned differently across minority and dominant cultures. The significance of this construction of the diasporic subject is its insistence that racialised identities, as they are lived and experienced, are far from being homogenous and biologically constituted categories. Just as one's sense of gender is indeterminate and mediated by race, class, sexuality and capacity, one's sense of racial identification is also thus shaped, producing identities that are partial and indeterminate.

However, it is the social construction of gender that disrupts the centrality of racial identification in both novels. Even though there are thirteen years separating the publication of the two novels, each of which focus on two distinct racialised subjects, it is the en(gender)ing of these young women's identities that creates a commonality of experience between the racially disparate Josephine and Amal. In other words, the 
evident symmetry between the two protagonists' struggle to forge a whole and unified identity in-between and across diverse cultural communities is not as much about race as it is about gender and, more specifically, the attainment of a female sexuality that is symbolically and materially acceptable across their respective minority and dominant cultures. For example, Josephine's mother's, Christina's, pregnancy outside of wedlock and Josephine's consequent illegitimacy means that they are neither accepted in Italian nor Australian communities, a status that is exacerbated by Josephine's grandmother's, 'Nonna Katia's', unyielding criticism of both women's supposed lack of (sexual) moral virtue:

The reaction of the Italian mothers to my mother being unmarried drove me crazy at times. There is nothing terribly romantic about my mother's supposed fall from grace. She slept with the boy next door when they were sixteen and before anything could be decided his family moved to Adelaide... I don't know where the logic is but back then no one was allowed to come and stay at my house. I knew they wanted to, yet I never understood why they couldn't. God knows what their parents thought my mother would do or say to their children (Marchetta 1992: 7)

I had a one hour 'hating Nonna' session. I hated her because she never had anything nice to say about Mama. I hated her because she'd never let my mother forget the past (Marchetta 1992: 40)

For Amal, the desire to embrace her Islamic identity through the wearing of the hijab is set against real and perceived fears about how others will respond. Her concerns arise, however, not from her avowed demonstration of her Islamic faith but from the pressure to conform to a Westernised construction of feminine identity - an ideal that places high value on personal image and the capacity to achieve a femininity that is simultaneously sexualised (and therefore provocative and appealing) and de-sexualised (and therefore chaste and virtuous):

I pull my floor-length mirror off my bedroom wall and put it up against an armchair, turning our family room into a communal dressing room. I then try on every single outfit I have and mix and match all my clothes with assorted coloured scarves as I dance to a J. Lo track. I try different styles with the scarves and attempt to figure out which shape makes my face look slimmest (Abdel-Fattah 2005: 16)

What's happened to me? Haven't I decided to wear the hijab because I feel proud of who I am? Suddenly I'm too chicken to go to a café? (Abdel-Fattah 2005: 74) 
Radical feminists have long argued that "the divisions of labour and allocations of power in patriarchy demand not merely a suffering [Woman and] Mother, but one divested of sexuality: The Virgin Mary, virgo intacta, perfectly chaste" (Adrienne Rich, 1979, cited in Walker, 1998: 136). From this perspective the construct of 'woman', and paradoxically the construct of the 'mother', has largely been made sense of through a dichotomy that positions her as either 'Madonna' or 'whore'. Arguably, this is a construction of femininity that has peculiarity only to Western societies and which has been argued for the most part by white Western middle-class feminists (for whom the signifier of the Madonna has particular resonance). Nonetheless, its relevance to postcolonial studies of the diasporic female subject in Western contexts should not be readily discounted.

For both Josephine and Amal, the struggle of being suspended in-between two cultures is primarily rooted in their experience of oppressive constructions of feminine sexuality that demand the simultaneous and incongruous restraint and release of sexual desire. These constructions are shown to be powerfully imbricated in each girl's sense of ethnic identification. It is feminine sexuality, therefore, that becomes the point at which race and gender truly intersect and consequently, where issues of race can work to disguise and legitimate the more universalised oppression of women on the basis of gender. This point is illustrated most powerfully in a conversation between Josephine and her boyfriend, Jacob:

'I had no hassles in my life before I met you. Now everywhere I turn I face a brick wall. I'm always giving you time. I can't sleep with you because you need time. I can't meet your grandmother because you need time...'

'This is why it'll never work between us, Jacob. We live two different lives and you can't understand that. Why can't you understand my life? Things aren't as easy for me as they are for you. You can do whatever you please but I can't because there are some things that could offend people I love. You live with such freedom, Jacob. You live without religion and culture. All you have to do is abide by the law' (Marchetta 1992: 206)

And, in a conversation between Amal and her friend, Leila, about the latter's relationship with her mother:

'Sometimes she has a hernia. Other times she tries to reason with me. You think you lawyer you get job with hijab? Who take you? Why you want work hard for nothing? They see your hijab and they refuse.'

'Someone will employ us,' I say.

'I wouldn't fight so hard if I didn't believe that someone wasn't out there.' 
I pause and then it hits me. 'Me either.' And I mean it (Abdel-Fattah 2005:

213)

\section{The veil as more than a marker of race and chaste femininity}

The hijab, or the veil as it is commonly referred to, is one of the most widely recognised signifiers of the intersections of 'race' and 'gender', and more specifically of being 'Arab/Muslim' and 'female'. Despite the wearing of the hijab as a stark marker of Islamic and/or Arab womanhood, it has tended to create two opposing positions - the veiled position and the feminist position, each of which has exposed (or has been purported as such) sharply contrasted views on both sides of the debate. In this debate, there is no power of ambiguity or hybridity for the wearer of the hijab - she is either completely 'virtuous' or completely 'oppressed'. For Lama Abu Odeh (1997: 253) who acknowledges the complexities of identifying both as an Arab and a feminist, the veiled body is anything but a monolith, revealing instead 'a multiplicity that is beyond the feminist's wildest expectations.' She states that:

a veiled woman is not necessarily either this or that. She could shift from one position to the other. At times colourful, other times bland, seductive and prudish, public and private. A veiled woman's subjectivity appears to be much more complicated than the simple word of the veil can possibly convey (Odeh, 1997: 254).

The fictional Amal reflects Odeh's view of the multiplicity of veiled sexuality and its potential to invite conversation between the 'same', rather than focus attention on the 'difference' of the 'other'. As a diasporic subject, Amal is neither completely 'oppressed' nor entirely 'virtuous'. Moreover, she is highly conscious of the dominant cultural gaze that constructs her identity in such falsely dichotomous terms. She talks openly about the advantages of wearing the hijab in terms of its capacity to connect her to her community and to her religion and about its disadvantages in relation to its potential to disconnect her from the dominant culture and from the more Westernised aspects of her identity, but she does so in terms of it being her choice to wear the hijab or not:

'It's up to me whether I want to [wear the hijab] or not!' I'm acting like I've already made the decision. I haven't, but the thought that somebody else might take that choice away from is energising something inside me. Call it what you want. Defiance. Pig-headedness. It's burning me to think that I might not have the right to choose (Abdel-Fattah 2005: 21)

Furthermore, her 'inner' debate is not just about whether to wear the hijab or not to wear it but also about how and when to wear it. In this way, she represents the diversity 
of women who wear the hijab - the puritans, the tentative and wavering, those who wear make-up with the veil and attempt to make it colourful and varied, those who retain an ambivalent relationship with it - sometimes wearing it and sometimes not, and those who wear it when they want to make a statement about who they are in different contexts (Odeh, 1997). In the self-conscious debate that takes place inside her head, Amal is using the power of ambivalence to create an identity that is intercultural, fluid, and potentially empowering:

I'm experiencing a new identity, a new expression of who I am on the inside, but I know that I'm not alone... I'm sharing something with millions of other women around the world and it feels so exciting. I know some people might find it hard to believe but walking around Chadstone tonight I'd never felt so free and sure of who I am. I felt safe that people weren't judging me and making assumptions about my character from the length of my skirt or the size of my bra. I felt protected from all the crap about beauty and image... I still dressed to impress and I took ages to get my make-up, clothes and hijab just right. But I didn't feel I was compromising myself by wanting to make an impression (Abdel-Fattah 2005: 25-26).

\section{The 'othered' versus the 'non-human'}

Unlike the previous two novels, 'Girl Underground' does not deal with the personal effects of diaspora on its female protagonist, Bridget. Rather, the novel uses Bridget's whiteness and the relative privilege it affords her to look at diaspora from the perspective of an outsider - not as an outsider to difference per se but as an outsider to the racial configurations of the refugee and the refugee camp.

Bridget is a young girl from a working class family who earns its living primarily from selling stolen goods. Nonetheless, Bridget's parents are loving and caring and want the best for their daughter, and even though they can barely afford it, they send Bridget to a prestigious school in the hope that she will have a successful and law-abiding future. It is at this new school that Bridget meets a fellow student by the name of Menzies who is a strong advocate for refugees in detention and the son of a prominent politician in the Australian Federal government. In some respects, Bridget conveys the pain of 'otherness' in terms of her classed position and her associated feelings of inferiority in attending a school at which she feels out of place amongst her wealthy peers. Her displacement is intensified by her constant concern that people will discover that her family trades in merchandise that 'falls off the back of a truck'. 
However, Bridget's classed position and her family's 'criminality' serve a much more valuable purpose in this novel than merely highlighting classed 'othering'. Bridget's family's 'criminality' along with her brother's six-month incarceration in an Australian gaol for theft, is juxtaposed against Jamal and Bibi's childhood innocence and incarceration at the hands of the Australian government's refugee policy. This juxtapositioning serves to disrupt the symbolic 'criminalisation' of the 'Arab Other' (Poynting, Noble, Tabar \& Collins, 2004) by drawing attention to the privileging of 'whiteness', despite its classed dimensions, and the unjustified imprisonment of the 'terrified', rather than 'terrorising', Arab asylum seeker.

Most significantly, the novel experiments with the premise that not everything is what it appears to be. For example, Bridget's family's criminality is juxtaposed against its members' strong sense of decency and generosity, demonstrating that just because one is a criminal does not necessarily mean that one does not live by a strong moral code. Bridget's classed position provides her with an anxious 'sense of being different from' her peers, demonstrating that being white and therefore part of the dominant culture does not necessarily mean that one has a sense of being the same as other white people. The novel's deliberate juxtapositioning of morality with criminality and of whiteness with difference forms an important backdrop to the novel's most pivotal message to young people: that a detained refugee of Arab descent is not necessarily, and is probably not, a terrorist in waiting. In this sense, Girl Underground attests to Salman Rushdie's contention that "the novel is one way of denying the official, politicians' version of truth" (2006: 430).

Bridget does not know Jamal and Bibi personally, but she hears about their plight through the letters Menzies' receives from their father, Mohammed. Her innocent compassion for two children who she views as being imprisoned through no fault of their own highlights not only the pain and injustice of child refugee detention but its overwhelming hypocrisy in terms of its circumvention of Australia's laws in relation to child protection and welfare:

Bridget: 'There are kids locked up in there,' I say to the camera. 'Kids who haven't done anything wrong. They haven't burgled anyone or shoplifted anything or even thought about robbing a bank.'... 'I met the Prime Minister last week,' I say. 'He said these kids are being locked up for us, the people of Australia. We're only four people, but we're here because we don't want any 
kids to suffer for us. My dad reckons that's how all Australians used to feel. I wish they still did' (Gleitzman 2004: 157-158).

It is here that the concept of 'otherness' is given its greatest meaning. In this paper I have used the term 'otherness' to indicate the process of being actively constituted as 'other' in relation to 'one', rather than 'other' itself having a fixed or essential identity or social position. The suggestion that 'otherness' is:

a fluid, socially constituted, repeatedly performed relationship, rather than a stable essence, challenges the notion of an 'other' as naturally different from, and properly subordinate to, a dominant category of normal self' (Ramazanoğlu, 2004: 108).

Paradoxically, the notion of 'otherness', therefore, whilst having its greatest relevance here, cannot adequately accommodate the spectre of diaspora constructed in this novel or in any construction of the detained refugee for that matter.

There are two angles to this argument. The first is that the concept of 'otherness' while invoking a dichotomy, actually assumes through the creation of this dualism, a commonality of identity - for example, post-structural feminists have long held that whilst 'woman' has been constructed as 'man's' 'other', the meaning of 'man' is dependent on its relationship to 'woman'. In the same way, the Arab 'other' is given meaning through its relationship to the normative 'one'. The second point to the argument is that in the case of refugee detention, however, there can be no 'other' because any shared humanity or common identity has been broken down by the 'complete displacement' of the refugee - she belongs neither here nor there - she is not this or that. In this sense then, the detained refugee becomes a 'non-citizen' and a 'nonhuman being'. Her 'difference' is not only of language and meaning but also of separation from her own humanity - at worst, her humanity does not exist and at best, it is indeterminate. In this sense, Jamal and Bibi's positioning as the 'other' would be a position of relative privilege rather than of subordination as one can only be 'othered' if one is deemed to be somehow related to the 'normative'/‘human' one in the first place.

Giorgio Agamben's work, Remnants of Auschwitz: the Witness and the Archive (1999) adds another important dimension to the 'human/non-human' binary I invoke here. His discussion of the Muselmann, the term used to describe the people dying of malnutrition in Auschwitz, highlights the impossibility of being able to distinguish between man and non-man within the confines of the camp. According to Agamben (1999: 47), the 
Muselmann inhabits the "extreme threshold between life and death, the human and the inhuman..."

At times a medical figure or an ethical category, at times a political limit or an anthropological concept, the Muselmann is an indefinite being in whom not only humanity and non-humanity, but also vegetative existence and relation, physiology and ethics, medicine and politics, and life and death continuously pass through each other. This is why the Muselmann's "third realm" is the perfect cipher of the camp, the nonplace in which all disciplinary barriers are destroyed and all embankments flooded (Agamben, 1999: 48).

Auschwitz was an extermination camp as well as a concentration camp and therefore, it may be extreme, if not morally negligent, to compare contemporary detention in Australia with Auschwitz or to compare Australian detainees with the Muselmann. However, there are still continuities and parallels to be drawn here. Apart from the numerous reports and allegations of abuse and ill-treatment in Australian detention centres, there have also been many stories about the self-imposed starvation of refugees, most notoriously involving the actual sewing together of the lips. The sheer desperation involved in these actions attests to the "extreme situation" of Australian detention and it is here where connections to the camp can be adequately drawn. Bruno Bettelheim, who had spent time in two Nazi concentration camps (not Auschwitz) and who had witnessed Muselmänner first hand, was one of the first to recognise the transformations that "extreme situations" produced in the personalities of camp prisoners, and it was precisely these experiences that had so thoroughly infused his subsequent work on childhood autism (Agamben, 1999). For Bettelheim the camp is the archetypal extreme situation and thus:

allows for the determination of what is inhuman and human and, in this way, for the separation of the Muselmann from the human being (Agamben, 1999: 48).

Thus, the Muselmann is the quintessential signifier of the camp and the camp is the ultimate creator of the non-human. In this scheme, there is no 'other', only a "third realm" wherein humanity and inhumanity co-exist. For the Muselmann, this coexistence hangs in the balance between life and death. It is Agamban's discussion of this 'life and death limbo' that highlights the most important connection between the issue of race and the formation of the non-human in the camp:

The Muselmann embodies the anthropological meaning of absolute power in an especially radical form. Power abrogates itself in the act of killing. The death of the other puts an end to the social relationship. But by starving the other, it gains time. It erects a third realm, a limbo 
between life and death. Like the pile of corpses, the Muselmänner document the total triumph of power over the human being. Although still nominally alive, they are nameless hulks. In the configuration of their infirmity, as in organized mass murder, the regime realizes its quintessential self (Sofsky, 1997, cited in Agamben, 1999: 47-48).

Drawing on the work of Foucault, Agamben postulates that racism is exactly what allows biopower to create caesuras in the biological continuum of the humans species, thus re-establishing a principle of war into the arrangement of "making live" the Muselmann, if only barely. Biopolitical caesuras are inherently moveable and thus continue to mark out a further zone in the biological continuum - the non-Aryan passes into the Jew, the Jew into the deportee, the deportee into the prisoner - until biopolitical caesura reach their final limit in the camp in the form of the Muselmann. At this point, the biopolitics of racism transcends race, piercing into a threshold where it is not longer possible to create caesuras. What emerges is something that cannot be assigned to a particular subject or be divided by another caesura. In this way, the production of the Muselmann is the final biopolitical substance to be isolated in the biological continuum. In this scheme, there is no 'race' and there is no 'other' because human life transcends every assignable biopolitical identity, the side effect of which is death (Agamben, 1999).

The story of Girl Underground is almost entirely constructed around the struggle to free Jamal and Bibi from its central villain - the camp - but the voices of these children are never heard and we never witness their suffering first hand; the reader only knows their plight through their father's letters and through the narratives of Bridget and Menzies. Jamal and Bibi's separation from their parents and Bibi's lack of access to appropriate medical care is the 'thin end of the wedge' in the detention centre's formation of the Muselmann. But, it is Jamal and Bibi's 'deafening' silence and 'vivid' invisibility that so convincingly mimics the spectre of the Muselmann and therein the atrocities of the camp/detention:

They crowd my memory with their faceless presence, and if I could enclose all the evil of our time in one image, I would choose this image which is familiar to me: an emaciated man, with head dropped and shoulders curved, on whose face and in whose eyes not a trace of thought is to be seen (Levi, 1986, cited in Agamben, 1999: 44).

Outside of detention, Jamal and Bibi would have access to the human rights accorded to all Australians. Inside detention, however, Jamal and Bibi become the Muselmänner, 
the 'non-human', where these rights become irrelevant and inapplicable. In its denial of these rights, the camp strips the dignity and humanity from the human being, helping to justify its assignment of the status of 'non-human' in the first place.

\section{The creation of hybrid identities and a position of shared humanity}

Josephine and Amal's struggle to forge an identity within and beyond the designations of race and ethnicity takes place across two domains - the 'outside world' being the dominant culture, of which they are both a part and a minority, and the 'inside world' of their own racialised communities. While Josephine finds it difficult to achieve a sense of belonging in either world, Amal is supported by her family and friends (albeit with much trepidation) to embrace her Islamic faith and encouraged to make her own way in the 'outside world'. Nevertheless, Amal is not spared from experiencing the devastation of not fully belonging in either domain. This phenomenon is most poignantly manifested in Amal's feelings of shame about how she responded to the situation of her friend Leila, a young Muslim woman who is torn between her desire for academic achievement and career and the need to acquiesce to her parents' will that she leaves school and enters into an arranged marriage:

I feel guilty. I never tried to bring Leila and her mum together. I never gave myself the chance to see things from Leila's mum's perspective and to understand her fears. It was easier to dismiss her as an ignorant villager. All those times I laughed behind her back... ridiculed her paranoia about us being harassed on public transport... It's not that I was arrogant. It's the fact that I felt that somehow, because I'm being education and brought up in an open-minded environment, I had the right to be arrogant and superior (Abdel-Fattah 2005: 314).

Both novels represent their female protagonists' trajectory through the painful terrain of racialised-gendered subjectification and the personal epiphanies they experienced along the way. For Josephine, the revelation that Nonna Katia had an affair with an Australian man and that her mother, Christina, was born from this union is ultimately emancipating. Josephine no longer has to feel ashamed about her unlikeness to Nonna Katia or about her inability to meet her grandmother's unattainable (de-sexualised) moral standards. She is free to view herself and her mother differently and to forge an identity that extends beyond that of illegitimate daughter:

I thought my birth circumstances were a cross I'd bear for the rest of my life, but what had happened between Nonna and Marcus Sandford made me realise that it had never been my cross. I had only made it mine (Marchetta 1992: 258). 
Similarly, Amal comes to the realisation that embracing her Islamic faith is an effort of profound self-consciousness rather than just a symbolic performance:

All this time I've been walking around thinking I've become pious because I've made the difficult decision to wear the hijab... but what's the good of being true to your religion on the outside, if you don't change what's on the inside, where it really counts? I've been kidding myself. Putting on the hijab isn't the end of the journey. It's just the beginning of it (Abdel-Fattah 2005: 314).

Josephine and Amal's personal crises are deeply rooted in their experience of displacement and belonging and of 'sameness' and 'otherness', which is as much gendered as it is raced. Thus, the resolution of these crises is shown to open up for each girl a new space in-between Italian/Palestinian-Muslim (gendered) and Australian (gendered) identity configurations. This new space does not create a 'raceless' subject but rather, a culturally hybrid one. Both Josephine and Amal are now able to view themselves as young Australian-Italian/Muslim women who, instead of having to choose between two cultures, are able to embrace their cultural heritage in a flexible third space - a third space "that entertains difference without an assumed or imposed hierarchy":

Josephine: If someone comes up and asks me what nationality I am, I'll look at them and say I'm an Australian with Italian blood flowing rapidly through my veins. I'll say that with pride, because it's pride that I feel (Marchetta 1992: 259).

Amal: Some people might find this ironic, but when I think about it, it's mainly the migrants in my life who have inspired me to understand what it means to be an Aussie. To be a hyphenated Australian... It's their stories and confrontations and pains and joys which have empowered me to know myself, challenged me to embrace my identity as a young AustralianPalestinian-Muslim girl (Abdel-Fattah 2005: 340).

In both novels, however, the achievement of hybridity is shown to be an ephemeral and incomplete state of being. Implicit in the close of both novels is that each young woman will continue to wrestle with and be transformed by the project of her identity - but that each is 'becoming' a subject by living "with and through, not despite, difference; by hybridity" (Hall, 1990: 238).

For Jamal and Bibi and their parents, however, there is no capacity for the development of a culturally hybrid identity as their status as non-citizens/humans relegates them to the periphery of the 'same'/'other' binary; that final biopolitical substance. They do, however, invoke a different dualism - that of 'human' and 'non-human' - and it is on 
this basis that the opportunity for the development of a 'collaboration of humanity', or more accurately, a 'collaboration of the human' is shown to emerge. Through their attempt to free Jamal and Bibi from the detention centre, Bridget and Menzies, with the help of their families, mobilise a 'human' resistance to the ethos of the camp - a kind of 'counter camp' - in which the humanity of the Muselmänner, the central paradox, is momentarily restored:

Bridget: Several of the journalists here have told me that nothing like this has ever happened inside an Australian detention centre before. I can believe it. There probably hasn't been this much hugging anywhere in Australia before. And nobody's been arrested, including us. The government must have decided that with so much media here, and so many voters, mass violence and arrests wouldn't looks so good... Menzies' dad is really impressed. He's planning to resign from the government and stand as an independent at the next election and I think he wants Dad to help him. He was saying just now that seeing all these ordinary Australians hugging and laughing with refugees gives him some really good clues about how a lot of people are going to vote (Gleitzman 2004: 183-184).

\section{Conclusion}

Despite the obvious differences between the three novels, the evident symmetry in the way each have conceptualised diaspora suggests that what it means to be a racialised subject in Australia is not so much a product of the peculiarities of race but rather the significance of all-at-once 'belonging' and 'not belonging', of 'inclusion' and 'exclusion', of 'sameness' and 'otherness' in relation to the dominant culture, and of 'freedom' and 'detention', and therefore of 'humanity' and 'non-humanity'. All three novels, in disparate ways, show the pain and disconnection for the subject of diaspora, not in terms of the peculiarities of biological race but in terms of race as a socially constituted experience that is also unavoidably gendered and classed, and contextualised by individual performativity (eg. the wearing of the hijab) and by circumstance (eg. detention).

Teenage fiction dealing with the themes of diaspora and the meaning of racialised identification for the subject must become an integral part of the school curriculum, not just for the purpose of literacy development but more so for the cultivation of young people's capacity for civic engagement and participation in Australia's increasingly culturally diverse and pluralistic society. This kind of teenage literature carries with it an implicit pedagogy about what it means to be a racialised female subject in Australia, and in so doing, creates the potential to subvert oppressive binary dualisms of race and 
gender. In the three texts examined here, binaries of race and racial identification are shown to be inherently differentiated and unstable because they are imbricated by gender, class, religion, sexuality and generation, thus giving rise to a multiplicity of ways of being racialised. Contemporary Australian teenage literature has the capacity to tap into and convey these multiplicities, producing insights that can assist young people in dealing with the existential question of: how are we to live together in the world?

\section{References}

Abdel-Fattah, R. (2005) Does my head look big in this? Sydney, Pan MacMillan Australia Pty Ltd.

Agamben, G. (1999) Remnants of Auschwitz: the Witness and the Archive (translated by Daniel Heller-Roazen), New York: Zone Books.

Ang, I. (1996) "The curse of the smile: ambivalence and the "Asian" woman in Australian multiculturalism", Feminist Review Vol. 52: 36-49.

Ang, I. (2001) On not speaking Chinese: Living between Asia and the West, London: Routledge.

Ashcroft, B., Griffiths, G. \& Tiffen, H. (Eds.) (2006) The Post-Colonial Studies Reader ( $2^{\text {nd }}$ Edition), London: Routledge.

Bhabha, H. (1994) The Location of Culture, New York: Routledge.

Gleitzman, M. (2004) Girl Underground, Australia: The Penguin Group.

Hall, S. (1990) "Cultural Identity and Diaspora", Identity: Community, Culture, Difference (Ed. Rutherford, J) London: Lawrence and Wishart.

Jefferson, A. (1982) "Structuralism and Post-Structuralism", in A. Jefferson \& D. Robey (eds) Modern Literary Theory: A Comparative Introduction London, Batsford Academic \& Educational Ltd.

Marchetta, M. (1992) Looking for Alibrandi, Victoria: Penguin Books Australia Ltd.

Odeh, LA (1997) "Post-colonial feminism and the veil: Thinking the difference", in M.M. Gergen, \& S.N. Davis (eds) Toward a new Psychology of Gender: A Reader New York: Routledge.

Poynting, S, Noble, G, Tabar, P \& Collins, J (2004) "The Arab Other" in Bin Laden in the Suburbs: Criminalising the Arab Other, Sydney: Sydney Institute of Criminology Series.

Ramazanoğlu, C (with Janet Holland) (2002) Feminist Methodology: Challenges and Choices, London: Sage Publications.

Rushdie, S (2006) "Imaginary Homelands", in B. Ashcroft, G. Griffiths, \& H. Tiffen, (eds)) The Post-Colonial Studies Reader ( $2^{\text {nd }}$ Edition) London: Routledge.

Walker, MB (1998) Philosophy and the Maternal Body: Reading Silence, London: Routledge.

Walkerdine, V (1984) "Someday my prince will come: young girls and the preparation for adult sexuality", in A. McRobbie \& M. Niva, M (eds) Gender and Generation, England: Macmillan. 
Young, R (1995) Colonial Desire, London: Routledge. 